\title{
ANÁLISE DA POLÍTICA DE INCLUSÃO ESCOLAR EM UM MUNÍCIPIO NA
} PERSPECTIVA DE PROFESSORES

\author{
ANÁLISIS DE LA POLÍTICA DE INCLUSIÓN ESCOLAR EN UN MUNICIPIO DESDE \\ LA PERSPECTIVA DEL PROFESOR
}

\author{
ANALYSIS OF THE SCHOLAR INCLUSION POLICY IN MUNICIPALITY IN \\ TEACHERS PERSPECTIVE
}

\author{
Vivian SANTOS ${ }^{1}$ \\ Enicéia Gonçalves MENDES ${ }^{2}$
}

RESUMO: No Brasil, a política de escolarização dos estudantes Público-Alvo da Educação Especial (PAEE) no sistema educacional geral iniciou-se há mais de duas décadas, resultando na ampliação de matrículas, mas ainda está longe de garantir acesso ao currículo. A questão emergente é: como avaliar e monitorar a política de inclusão escolar para averiguar se os resultados apontam ou não para avanços do direito à educação provida para alunos PAEE? O presente estudo, baseado no referencial teórico metodológico da Abordagem do Ciclo de Políticas, objetivou analisar o contexto de influência e de prática e oferecer subsídios para melhor equacionar a política de inclusão escolar de um município. A metodologia, do tipo multimétodo, envolveu a participação de 46 professores de sete escolas, com técnicas de análise documental, entrevista coletiva e questionário fechado. Os resultados permitiram gerar 43 indicadores, distribuídos em 13 quesitos, e, no conjunto das sete escolas, com sete quesitos bem avaliados, quatro com índices regulares e dois considerados fracos. No conjunto evidenciou-se diferentes efeitos da política de um mesmo município nas sete escolas e permitiu-se apontar aspectos nos quais a qualidade da política pode melhorar.

PALAVRAS-CHAVE: Educação especial. Inclusão escolar. Ciclo de políticas.

RESUMEN: En Brasil, la política de escolarización para estudiantes con Necesidades Educativas Especiales (NEE) en el sistema de educación general comenzó hace más de dos décadas, lo que resultó en la expansión de la matrícula, pero aún está lejos de garantizar el acceso al plan de estudios. La pregunta emergente es ¿cómo evaluar y monitorear la política de inclusión escolar para determinar si los resultados apuntan o no a avances en el derecho a la educación brindado a los estudiantes con NEE? El presente estudio, basado en el marco teórico metodológico del Enfoque de Ciclo de Políticas, tuvo como objetivo analizar el contexto de influencia y práctica y ofrecer subsidios para mejorar la política de inclusión escolar de un municipio. La metodología, de tipo multimétodo, contó con la participación de

\footnotetext{
${ }^{1}$ Universidade Federal de São Carlos (UFSCAR), São Carlos - SP - Brasil. Doutoranda no Programa de PósGraduação em Educação Especial. ORCID: https://orcid.org/0000-0001-7694-4890. E-mail: vivi.eesp@gmail.com

${ }^{2}$ Universidade Federal de São Carlos (UFSCAR), São Carlos - SP - Brasil. Professora Titular do Departamento de Psicologia. Doutorado em Psicologia (USP). Bolsista de Produtividade em Pesquisa do CNPq - Nível 1B. ORCID: https://orcid.org/0000-0003-3673-0681.E-mail: egmendes@ufscar.br
} 
46 docentes de siete escuelas, con técnicas de análisis documental, entrevista colectiva y con cuestionario cerrado. Los resultados permitieron generar 43 indicadores, distribuidos en 13 items, y en el conjunto de siete escuelas, con siete items bien evaluados, cuatro con índices regulares y dos considerados débiles. En su conjunto, los diferentes efectos de la politica de un mismo municipio se evidenciaron en las siete escuelas y permitieron señalar aspectos en los que la calidad de la política puede mejorar.

PALABRAS CLAVE: Educación especial. Inclusión escolar. Ciclo de políticas.

ABSTRACT: In Brazil, the schooling policy for students with Special Educational Needs (SEN) in general education system began more than two decades ago, resulting in the expansion of enrollments. However, it is still far from guaranteeing access to the curriculum. The emerging question is how to evaluate and monitor the school inclusion policy to ascertain whether the results point to advances in the right to education provided for SEN students? The present study, based on the theoretical methodological framework of the Policy Cycle Approach, aimed to analyze the context of influence and practice and offer subsidies to address the school inclusion policy of a municipality. The methodology, a multimethod type, involved the participation of 46 teachers from seven schools, with techniques of document analysis, collective interview and with structured questionnaire. The results allowed generating 43 indicators, distributed in 13 items, and in the set of 7 schools, and seven items well evaluated, four resulted in regular indexes and two items considered weak. As a whole, different effects of the policy of the same municipality were evident in the seven schools and allowed to point out aspects in which the quality of the policy can improve.

KEYWORDS: Special education. School inclusion. Policy cycle.

\section{Introdução}

O desenho traçado por determinada política é a forma como a sociedade busca definir suas linhas de ação a partir de seus valores éticos (BALL, 1990). Na política de escolarização de estudantes Público-Alvo da Educação Especial (PAEE), no contexto mundial, houve época em que essas pessoas sequer eram consideradas educáveis. Posteriormente, quando as escolas se popularizam, elas conquistaram a oportunidade de ingresso, mas em contextos separados de escolas e instituições especiais. E foi somente a partir da década de 1970 que a escolarização delas em escolas comuns começa a ser mundialmente cogitada. Essas influências do contexto internacional também aportam no Brasil, tendo impactos diferentes num país de dimensões continentais, com 26 sistemas de ensino estaduais, mais o sistema do Distrito Federal, além das 5.570 realidades distintas nos municípios.

Larner e Laurie (2010) estudam como os múltiplos atores, geografias e traduções estão envolvidos nos processos de transferência de políticas, que chamam de "glocalização", os interjogos entre as formas globais com circunstâncias locais. Nesse sentido, Ball (2005) 
aponta elementos políticos como fatores de influência na conjuntura política, como: a) o neoliberalismo com o idealismo do mercado; b) as novas redes de governança; c) a performatividade e; d) a nova forma de gestão pública, que incorpora procedimentos específicos do setor privado, o culto à excelência e à qualidade. Assim, os macroprocessos pelos quais passam a expansão do mercado, das formas de vida, as modificações culturais implicadas pela lógica de novas formas de acumulação, distribuição e circulação do capital, impactam fortemente na governança dos países, estados e municípios sobre as novas necessidades de legitimarem os processos dos micros contextos na vida cotidiana das instituições (BALL, 2014).

No Brasil, a defesa da escolarização dos estudantes do PAEE no sistema educacional geral vai aparecer como conjugação de forças entre movimentos nacionais próprios das pessoas com deficiência e de influências das convenções internacionais, promovidas por organismos multilaterais que forjaram reformas educacionais nos anos de 1990. Entretanto, foi a partir de 2003, e no bojo da reorientação das políticas educacionais com novas alterações nas legislações desde a educação básica até a superior (DOURADO, 2007), que emergiram programas e ações que tinham como objetivo ampliar o acesso à escolarização em classes comuns de escolas regulares aos alunos do PAEE. A partir daí observa-se o incremento de matrículas de estudantes PAEE escolarizados em classes comuns em todo o país, que passou de 110.536 em 2002 para 1.090.805 em 2019 (INEP, 2002; 2019).

A Lei 13.005/2014, que aprovou o Plano Nacional de Educação (PNE), anunciou na Meta 4 a necessidade de universalizar o acesso às escolas e ao Atendimento Educacional Especializado (AEE) para estudantes do PAEE nos próximos 10 anos, reconhecendo que o país ainda precisava assegurar escola e qualidade de ensino a essa parcela da população. $\mathrm{O}$ PNE previu ainda que o poder público buscaria ampliar o escopo de pesquisas sobre o perfil das populações de quatro a 17 anos, com deficiência, para avaliar e acompanhar as metas estabelecidas (BRASIL, 2014).

Entretanto, no caso específico da meta 4, que diz respeito à Educação Especial, os indicadores quantitativos pouco permitem acompanhar a evolução do direito à educação dos estudantes PAEE, dado que muitos alunos sequer participam das avaliações de larga escala conduzidas no país (MENDES; CIA; TANNÚS-VALADÃO, 2015), além do que os processos de identificação do PAEE nos sistemas de ensino ainda são precários (SANTOS, 2017).

Assim, a questão que se coloca é a de como avaliar e monitorar a política de inclusão escolar para averiguar se os resultados apontam ou não para avanços do direito à educação 
para alunos PAEE, e o presente estudo focaliza essa questão, tendo como referencial analítico a Abordagem do Ciclo de Políticas (ACP) (BOWE; BALL; GOLD, 1992) e Teoria da Atuação de políticas (BALL; MAGUIRE; BRAUN, 2016).

A ACP consiste em uma ferramenta teórico-metodológica para estudos de políticas educacionais (MAINARDES; MARCONDES, 2009), que propõe o estudo de um ciclo contínuo composto por três contextos inter-relacionados: de influência, de produção de texto e de prática. Os três contextos não possuem uma sequência de etapas lineares, dimensão temporal ou sequencial (BOWE; BALL; GOLD, 1992).

O contexto de influência consiste no espaço em que as políticas públicas têm início, ou o espaço em que os discursos políticos são construídos e os conceitos chaves são definidos. $\mathrm{O}$ contexto de produção de textos envolve os documentos oficiais, comentários formais ou informais que visam dar sentido a textos oficiais. As respostas aos textos são dadas por meio do terceiro contexto, de prática, no qual a política não é simplesmente implementada, mas sim interpretada e recriada pelos atores do espaço escolar (BOWE; BALL; GOLD, 1992).

A Teoria da Atuação sugere levar em consideração as dimensões contextuais da política em quatro dimensões: contextos situados, culturas profissionais, contextos materiais e contextos externos (BALL; MAGUIRE; BRAUN, 2016). Nos contextos situados, considerase a maneira como os membros do corpo escolar construíram uma visão sobre as escolas em questão. As culturas profissionais dizem respeito à forma como os profissionais estão ligados a uma equipe e a maneira como a função de cada um impacta sua compreensão da política. Os contextos materiais são os aspectos físicos das escolas, sua equipe e infraestrutura. Por fim, os contextos externos incluem pressões das avaliações externas e expectativas em relação a uma determinada escola e ao trabalho exercido pelos seus profissionais (BALL; MAGUIRE; BRAUN, 2016).

O presente estudo tem como objetivo analisar a política de inclusão escolar de um município baseada nas percepções de professores do ensino comum, com foco em elementos do contexto de influência e de prática, além de produzir subsídios para melhor equacionar a política analisada no município investigado.

\section{Metodologia}

O estudo envolveu um delineamento multimétodo ou misto (YIN, 2010), foi desenvolvido em uma rede municipal de cidade de pequeno porte do interior do estado de São Paulo, com estimativa populacional de cerca de 59 mil habitantes no ano de 2016 (SEADE, 
2017). O estudo foi aprovado pelo Comitê de Ética em Pesquisa em Seres Humanos (CEP) da Universidade Federal de São Carlos (Número do CAAE: 68140317.9.0000.5504).

$\mathrm{O}$ delineamento envolveu estudo de documentos oficiais do município, entrevistas com duas pessoas indicadas como sendo de referência no processo histórico da política de Educação Especial, análise de indicadores estatísticos das matrículas dos estudantes do PAEE, aplicação de um questionário estruturado com professores do ensino comum, além de entrevista coletiva com o grupo de professores participantes. Participaram do estudo 46 professoras do ensino comum, das quais a maioria tinha cursado licenciatura (98\%), 14 (30\%) tinham especialização na área de Educação Especial, 41 (89\%) lecionava nos anos iniciais do ensino fundamental, quatro $(9 \%)$ nos anos finais, e apenas uma (2\%) na pré-escola.

O instrumento utilizado foi o "Questionário de Análise da Política de Inclusão Escolar - Professores do Ensino Comum - QUAPOIE-PEC, terceira versão" (LACERDA; MENDES, 2016), composto por 292 itens, classificados em 13 quesitos e 42 indicadores. Os itens do questionário foram agrupados em indicadores, e estes agregados para compor os quesitos. Indicadores e quesitos poderiam atingir valores mínimos de 0 a máximo de 10 , e valores proporcionais ponderados foram atribuídos às alternativas de respostas de cada item, e a cada item, dependendo da relevância do mesmo para a composição daquele indicador. A partir dos valores totais dos indicadores foram obtidas as médias para o quesito. Os dados qualitativos foram coletados por meio de entrevista coletiva com audiogravação, posteriormente transcrita para complementar a análise dos dados quantitativos.

Para o presente estudo, devido à necessidade de delimitação, foram priorizadas as análises dos dados obtidos com os professores através dos questionários, e eventualmente, faz-se referência aos dados estatísticos, aos documentos e às entrevistas com gestores, a fim de melhor contextualizar a análise dos indicadores.

\section{A política de Educação Especial do município}

O município estudado foi fundado no final do século XVI, onde havia grande número de fazendas, sendo estabelecido um povoado no local por volta de 1800 , levando em torno de 75 anos para que este se tornasse uma cidade (IBGE, 2019). Em 2018, tinha uma população estimada de aproximadamente 60 mil habitantes.

A criação da instituição especializada da Associação de Pais e Amigos dos Excepcionais (APAE), no início na década de 1970, coincide com as primeiras inciativas do governo federal de política de Educação Especial no país (LAPLANE; CAIADO; KASSAR, 
2016). Essa política de institucionalização se manteve da década de 1970 a meados de 1990, e paralelamente foram criadas as classes especiais nas escolas estaduais do município.

Foi apenas a partir de 1996 que o município teve sua primeira iniciativa de inserção de alunos com deficiência na rede municipal, movimento este que coincide com o processo de municipalização do ensino fundamental. Na época, um serviço de apoio de uma equipe multidisciplinar da instituição especializada, conveniada com o município, começou a ser ofertado às escolas com matrículas de estudantes do PAEE.

Em 2005, com nova mudança na gestão municipal, esse serviço de apoio foi assumido pela prefeitura municipal, e o ideário de que o melhor local de escolarização seria a classe comum chegava também no contexto local, como reflexo do que se propagava no contexto nacional (BRASIL, 2004; MENDES, 2006).

Em 2008, o município aderiu à proposta da política do governo federal, conferindo centralidade aos serviços do AEE, transformando as antigas classes especiais em Salas de Recursos Multifuncionais (SRM), e mantendo uma sala de recursos para alunos com deficiência visual. Segundo os dados do censo escolar, havia cerca de 30 alunos do PAEE nas escolas municipais, antes de iniciar a política de inclusão escolar. Entre os anos de 2008 e 2010, esse número passou para cerca de 70 alunos. De 2010 a 2013 continuou a aumentar as matrículas, e a partir de 2013, ao contrário do que se observa no país, constata-se no município a diminuição contínua no número de matrículas desses alunos nas classes comuns. Esse decréscimo foi explicado pela gestão como resultante da adoção de critérios mais rígidos na identificação de alunos PAEE.

Em 2018, ano de início do presente estudo, a instituição da APAE realizava atendimento especializado aos alunos com deficiência intelectual classificados como "moderado" a "grave", que não frequentavam as escolas comuns. A configuração dos apoios na rede municipal envolvia o AEE nas SRM. Além disso, serviços indiretos eram ofertados pela equipe multidisciplinar, a qual oferecia, na época, formação continuada e projetos com focos específicos.

O estudo foi realizado em 2018 e 2019, nas sete escolas municipais com matrículas de alunos PAEE, denominadas de E1 a E7. E2 era a escola que possuía o maior número de alunos PAEE (17), seguida de E3 (11), E6 e E1 (8), E5 e E7 (7). Em relação ao gênero, havia predominância de alunos do PAEE do sexo masculino em todas as escolas estudadas, com proporções que variavam de 53\% (E2) a 100\% (E4). Em relação à categoria de PAEE, havia predominância de alunos com deficiência intelectual (37 alunos). Transtorno do Espectro do 
Autismo foi categoria com segunda maior incidência (15), seguido por deficiência física (9) e auditiva (8), baixa visão (4), deficiência múltipla (2).

\section{Qualidade da política de inclusão escolar no município baseada em indicadores na avaliação dos professores}

A análise dos resultados dos questionários resultou 42 indicadores, distribuídos em 13 quesitos. Os indicadores e quesitos poderiam atingir valores entre zero e dez, e foram assim classificados, para efeito da interpretação: pontuações entre 0 e 2,0 como insuficiente; 2,01 e 4,00 como fraco; 4,01 e 6,0 como regular; 6,01 e 8,00 como bom e 8,01 e 10 como muito bom. Os resultados obtidos para indicadores e quesitos nas escolas estudadas encontram-se na Tabela 1.

Tabela 1 - Relação dos índices obtidos nos indicadores por escola

\begin{tabular}{|c|c|c|c|c|c|c|c|c|}
\hline & E1 & E2 & E3 & $\mathbf{E} 4$ & E5 & E6 & E7 & M. \\
\hline I 1 & $7,67-B$ & $7,33-B$ & $8,00-\mathrm{B}$ & $8,00-\mathrm{B}$ & $8,00-\mathrm{B}$ & $7,20-B$ & $8,00-\mathrm{B}$ & $7,67-B$ \\
\hline I 2 & $5,50-\mathrm{R}$ & $6,90-\mathrm{B}$ & $6,14-\mathrm{B}$ & $5,00-\mathrm{R}$ & $7,30-\mathrm{B}$ & $3,20-\mathrm{F}$ & $6,25-\mathrm{B}$ & $4,54-\mathrm{R}$ \\
\hline \multicolumn{9}{|c|}{ Média geral do Quesito I - Formação: 6,75 - B } \\
\hline I 3 & $7,67-B$ & $7,33-\mathrm{B}$ & $8,00-\mathrm{B}$ & $8,00-\mathrm{B}$ & 8,00 - B & $7,20-\mathrm{B}$ & 8,00 - B & $7,67-B$ \\
\hline \multicolumn{9}{|c|}{ Média geral do Quesito II - Condições de trabalho: 8,34 - B } \\
\hline I 4 & $3,67-\mathrm{F}$ & $3,42-\mathrm{F}$ & $5,57-\mathrm{R}$ & $5,60-\mathrm{R}$ & $5,00-\mathrm{R}$ & $4,67-\mathrm{R}$ & $6,75-\mathrm{B}$ & $4,67-\mathrm{R}$ \\
\hline I 5 & $8,60-\mathrm{MB}$ & $7,10-\mathrm{B}$ & $8,86-\mathrm{MB}$ & $8,40-\mathrm{MB}$ & $8,83-\mathrm{MB}$ & $8,00-\mathrm{B}$ & $10,00-\mathrm{MB}$ & $8,35-\mathrm{MB}$ \\
\hline \multicolumn{9}{|c|}{ Média geral do Quesito III - Organização escolar: 6,75 - B } \\
\hline I 6 & $4,08-\mathrm{R}$ & $5,00-\mathrm{R}$ & $2,81-\mathrm{F}$ & $3,60-\mathrm{F}$ & $4,33-\mathrm{R}$ & $3,75-\mathrm{F}$ & $4,67-\mathrm{R}$ & $4,12-\mathrm{R}$ \\
\hline \multicolumn{9}{|c|}{ Média geral do Quesito IV - Identificação do PAEE: 4,03 - R } \\
\hline I 7 & $10,00-\mathrm{MB}$ & $9,88-\mathrm{MB}$ & $10,00-\mathrm{MB}$ & $10,00-\mathrm{MB}$ & $10,00-\mathrm{MB}$ & $9,67-\mathrm{MB}$ & $10,00-\mathrm{MB}$ & $9,92-\mathrm{MB}$ \\
\hline I 8 & $10,00-\mathrm{MB}$ & $9,88-\mathrm{MB}$ & $9,90-\mathrm{MB}$ & $9,00-\mathrm{MB}$ & $10,00-\mathrm{MB}$ & $8,67-\mathrm{MB}$ & $9,17-\mathrm{MB}$ & $9,57-\mathrm{MB}$ \\
\hline I 9 & $10,00-\mathrm{MB}$ & 9,94-MB & $10,00-\mathrm{MB}$ & $10,00-\mathrm{MB}$ & $10,00-\mathrm{MB}$ & $10,00-\mathrm{MB}$ & $10,00-\mathrm{MB}$ & $9,98-\mathrm{MB}$ \\
\hline I 10 & $9,17-\mathrm{MB}$ & $8,91-\mathrm{MB}$ & $10,00-\mathrm{MB}$ & $6,00-\mathrm{R}$ & $7,50-\mathrm{B}$ & $8,00-\mathrm{B}$ & $10,00-\mathrm{MB}$ & $8,63-\mathrm{MB}$ \\
\hline \multicolumn{9}{|c|}{ Média geral do Quesito V-Suportes pessoais para o aluno PAEE: 9,49 - MB } \\
\hline I 11 & $8,67-\mathrm{MB}$ & $6,83-\mathrm{B}$ & $8,57-\mathrm{MB}$ & $8,80-\mathrm{MB}$ & $6,17-\mathrm{B}$ & $8,17-\mathrm{MB}$ & $9,00-\mathrm{MB}$ & $7,83-\mathrm{B}$ \\
\hline I 12 & $7,33-\mathrm{B}$ & $5,58-\mathrm{R}$ & $5,14-\mathrm{R}$ & $4,00-\mathrm{F}$ & $4,83-\mathrm{R}$ & $5,17-\mathrm{R}$ & $6,00-\mathrm{R}$ & $5,46-\mathrm{R}$ \\
\hline I 13 & $1,67-\mathrm{I}$ & $0,83-\mathrm{I}$ & $1,43-\mathrm{I}$ & $2,00-\mathrm{I}$ & $0,83-\mathrm{I}$ & 0,83 - I & $0,00-\mathrm{I}$ & $1,09-\mathrm{I}$ \\
\hline I 14 & $6,00-\mathrm{R}$ & $2,08-\mathrm{F}$ & $2,14-\mathrm{F}$ & $1,00-\mathrm{I}$ & $0,00-\mathrm{I}$ & $2,50-\mathrm{F}$ & $1,25-\mathrm{I}$ & $2,20-\mathrm{F}$ \\
\hline I 15 & $0,83-\mathrm{I}$ & $3,58-\mathrm{F}$ & $4,29-\mathrm{R}$ & $4,40-\mathrm{R}$ & $0,00-\mathrm{I}$ & $2,83-\mathrm{F}$ & $4,00-\mathrm{F}$ & $2,89-\mathrm{F}$ \\
\hline I 16 & $0,00-\mathrm{I}$ & $2,08-\mathrm{F}$ & $2,29-\mathrm{F}$ & $2,20-\mathrm{F}$ & $2,50-\mathrm{F}$ & $3,50-\mathrm{F}$ & $0,00-\mathrm{I}$ & $1,91-\mathrm{I}$ \\
\hline \multicolumn{9}{|c|}{ Média geral do Quesito VI - Suportes pedagógicos para o aluno PAEE: 3,56 - F } \\
\hline I 17 & $10,00-\mathrm{MB}$ & $8,33-\mathrm{MB}$ & $10,00-\mathrm{MB}$ & $10,00-\mathrm{MB}$ & $9,17-\mathrm{MB}$ & $5,83-\mathrm{R}$ & $8,75-\mathrm{MB}$ & $8,80-\mathrm{MB}$ \\
\hline I 18 & $4,67-\mathrm{R}$ & $5,08-\mathrm{R}$ & $5,40-\mathrm{R}$ & $4,00-\mathrm{F}$ & $5,83-\mathrm{R}$ & $1,50-\mathrm{I}$ & $2,50-\mathrm{F}$ & $4,13-\mathrm{R}$ \\
\hline \multicolumn{9}{|c|}{ Média geral do Quesito VII - Gestão Democrática: 6,46 - B } \\
\hline I 19 & $5,33-\mathrm{R}$ & $5,58-\mathrm{R}$ & $9,00-\mathrm{MB}$ & $5,00-\mathrm{R}$ & $5,83-\mathrm{R}$ & $5,17-\mathrm{R}$ & $7,00-\mathrm{B}$ & $5,83-\mathrm{R}$ \\
\hline I 20 & $4,50-\mathrm{R}$ & $3,58-\mathrm{F}$ & $5,57-\mathrm{R}$ & $5,20-\mathrm{R}$ & $5,00-\mathrm{R}$ & $1,67-I$ & $3,75-\mathrm{F}$ & $4,13-\mathrm{R}$ \\
\hline \multicolumn{9}{|c|}{ Média geral do Quesito VIII - Planejamentos : 4,98 - R } \\
\hline I 21 & $8,00-\mathrm{B}$ & $6,50-\mathrm{B}$ & $6,71-\mathrm{B}$ & $8,20-\mathrm{MB}$ & $7,33-\mathrm{B}$ & $6,50-\mathrm{B}$ & $7,25-\mathrm{B}$ & $7,09-\mathrm{B}$ \\
\hline I 22 & $4,33-\mathrm{R}$ & $2,08-\mathrm{F}$ & $4,29-\mathrm{R}$ & $3,00-\mathrm{F}$ & $4,17-\mathrm{R}$ & $1,17-\mathrm{I}$ & $2,50-\mathrm{F}$ & $3,00-\mathrm{F}$ \\
\hline I 23 & $5,33-\mathrm{R}$ & $5,00-\mathrm{R}$ & $5,71-\mathrm{R}$ & $6,60-\mathrm{B}$ & $5,67-\mathrm{R}$ & $6,00-\mathrm{R}$ & $4,75-\mathrm{R}$ & $5,52-\mathrm{R}$ \\
\hline I 24 & $4,50-\mathrm{R}$ & $4,42-\mathrm{R}$ & $4,29-\mathrm{R}$ & 4,20 - R & $5,00-\mathrm{R}$ & $3,50-\mathrm{F}$ & $5,50-\mathrm{R}$ & $4,43-\mathrm{R}$ \\
\hline I 25 & $3,50-\mathrm{F}$ & $2,42-\mathrm{F}$ & $1,43-\mathrm{I}$ & $1,20-I$ & $4,00-\mathrm{F}$ & $1,33-\mathrm{I}$ & $2,50-\mathrm{F}$ & $2,35-\mathrm{F}$ \\
\hline \multicolumn{9}{|c|}{ Média geral do Quesito IX - Estratégias de ensino: 4,54 - R } \\
\hline I 26 & $4,17-\mathrm{R}$ & $3,50-\mathrm{F}$ & $6,43-\mathrm{B}$ & $4,00-\mathrm{F}$ & $4,33-\mathrm{R}$ & $2,33-\mathrm{F}$ & $1,25-\mathrm{I}$ & $3,85-\mathrm{F}$ \\
\hline I 27 & $8,00-\mathrm{B}$ & $5,67-\mathrm{R}$ & $4,71-\mathrm{R}$ & $9,20-\mathrm{MB}$ & $8,67-\mathrm{MB}$ & $6,17-\mathrm{B}$ & $6,25-\mathrm{B}$ & $6,72-\mathrm{B}$ \\
\hline I 28 & $7,00-\mathrm{B}$ & $4,83-\mathrm{R}$ & $6,86-\mathrm{B}$ & $9,20-\mathrm{MB}$ & $6,67-\mathrm{B}$ & $4,00-\mathrm{F}$ & $3,50-\mathrm{F}$ & $5,91-\mathrm{R}$ \\
\hline I 29 & $6,17-\mathrm{B}$ & $4,50-\mathrm{R}$ & $6,43-\mathrm{B}$ & $5,00-\mathrm{R}$ & $6,67-\mathrm{B}$ & $6,83-\mathrm{B}$ & $2,75-\mathrm{F}$ & $5,50-\mathrm{R}$ \\
\hline I 30 & $8,50-\mathrm{MB}$ & $7,58-\mathrm{B}$ & $6,57-\mathrm{B}$ & $8,00-\mathrm{B}$ & $9,33-\mathrm{MB}$ & $5,17-\mathrm{R}$ & $6,75-\mathrm{B}$ & $7,43-B$ \\
\hline I 31 & $0,00-I$ & $0,00-\mathrm{I}$ & $0,00-\mathrm{I}$ & $0,00-\mathrm{I}$ & $0,00-\mathrm{I}$ & $0,00-\mathrm{I}$ & $0,00-\mathrm{I}$ & $0,00-\mathrm{I}$ \\
\hline
\end{tabular}




\begin{tabular}{|c|c|c|c|c|c|c|c|c|}
\hline I 32 & $0,83-\mathrm{I}$ & $0,92-I$ & 0,14 - I & $0,80-\mathrm{I}$ & $2,00-\mathrm{I}$ & $0,17-\mathrm{I}$ & $0,25-\mathrm{I}$ & $0,76-\mathrm{I}$ \\
\hline I 33 & $8,17-\mathrm{MB}$ & $6,67-B$ & $7,00-\mathrm{B}$ & $6,60-\mathrm{B}$ & $8,33-\mathrm{MB}$ & $5,67-\mathrm{R}$ & $8,25-\mathrm{MB}$ & $7,13-B$ \\
\hline I 34 & $7,67-B$ & $5,92-\mathrm{R}$ & $6,71-\mathrm{B}$ & $7,40-B$ & $5,50-\mathrm{R}$ & $5,50-\mathrm{R}$ & $7,75-\mathrm{B}$ & $6,48-\mathrm{B}$ \\
\hline I 35 & $9,33-\mathrm{MB}$ & $9,42-\mathrm{MB}$ & $10,00-\mathrm{MB}$ & $9,00-\mathrm{MB}$ & $10,00-\mathrm{MB}$ & $8,83-\mathrm{MB}$ & $9,50-\mathrm{MB}$ & $9,46-\mathrm{MB}$ \\
\hline I 36 & $2,67-F$ & $1,67-I$ & $1,00-\mathrm{I}$ & $1,60-I$ & $4,17-\mathrm{R}$ & $2,17-\mathrm{F}$ & $4,50-\mathrm{R}$ & $2,33-\mathrm{F}$ \\
\hline I 37 & $6,00-\mathrm{R}$ & $5,00-\mathrm{R}$ & $4,71-\mathrm{R}$ & $8,00-\mathrm{B}$ & $5,33-\mathrm{R}$ & $7,33-\mathrm{B}$ & $8,75-\mathrm{MB}$ & $6,09-\mathrm{R}$ \\
\hline \multicolumn{9}{|c|}{ Média geral do Quesito XI - Interações: 6,46 - B } \\
\hline I 38 & $9,33-\mathrm{MB}$ & $8,42-\mathrm{MB}$ & $8,14-\mathrm{MB}$ & $8,20-\mathrm{MB}$ & $9,67-\mathrm{MB}$ & $8,50-\mathrm{MB}$ & $9,50-\mathrm{MB}$ & $8,74-\mathrm{MB}$ \\
\hline \multicolumn{9}{|c|}{ Média geral do Quesito XII - Atitudes em relação à inclusão escolar: 8,82 - MB } \\
\hline I 39 & $3,83-\mathrm{F}$ & $1,50-\mathrm{I}$ & $2,86-\mathrm{F}$ & $3,80-\mathrm{F}$ & $4,67-\mathrm{R}$ & $4,33-\mathrm{R}$ & $2,50-\mathrm{F}$ & $3,13-\mathrm{F}$ \\
\hline I 40 & $2,67-\mathrm{F}$ & $3,67-\mathrm{F}$ & $2,71-\mathrm{F}$ & $4,20-\mathrm{R}$ & $4,67-\mathrm{R}$ & $3,67-\mathrm{F}$ & $4,25-\mathrm{R}$ & $3,63-\mathrm{F}$ \\
\hline I 41 & $5,50-\mathrm{R}$ & $6,67-\mathrm{B}$ & $5,57-\mathrm{R}$ & $7,40-\mathrm{B}$ & $6,50-\mathrm{B}$ & $7,00-B$ & $5,75-\mathrm{R}$ & $6,37-\mathrm{B}$ \\
\hline I 42 & $0,00-\mathrm{I}$ & $0,33-\mathrm{I}$ & $0,29-\mathrm{I}$ & $0,00-\mathrm{I}$ & $0,33-\mathrm{I}$ & $1,00-\mathrm{I}$ & $0,00-\mathrm{I}$ & $0,30-\mathrm{I}$ \\
\hline
\end{tabular}

Fonte: Dados próprios obtidos por meio da análise dos resultados dos questionários QUAPOIE-C

Os índices gerais atingidos pelos 13 quesitos, no conjunto das sete escolas, permitiram evidenciar que dois deles (15\%) foram avaliados como muito bons, o Quesito V - Suportes pessoais para o aluno PAEE $(9,49)$ e o Quesito XII - Atitudes em relação à inclusão escolar $(8,82)$. Cinco quesitos (38\%) tiveram índices considerados bons $(38 \%)$, a saber, o Quesito I Formação $(6,75)$, o Quesito II - Condições de trabalho (8,34), o Quesito III - Organização escolar (6,75), o Quesito VII - Gestão Democrática (6,46), e o Quesito XI - Interações $(6,46)$. Quatro dos quesitos resultaram em índices considerados regulares (31\%): Quesito IV Identificação do PAEE (4,03), Quesito VIII - Planejamentos (4,98), Quesito IX - Estratégias de ensino (4,54), e Quesito X - Avaliação do ensino e da aprendizagem dos alunos PAEE $(4,90)$. Finalmente, dois quesitos $(15 \%)$ resultaram em índices considerados fracos, que foram: o Quesito VI - suportes pedagógicos para alunos PAEE $(3,56)$ e o Quesito XIII - Senso de auto eficácia dos professores regentes em relação ao ensino de alunos do PAEE $(3,42)$.

Em relação às escolas, considerando-se os 42 indicadores analisados, constatou-se que a proporção de índices considerados muito bons ou bons variou de 48\% (E3 e E7) a 36\% (E6). Por outro lado, a proporção de indicadores considerados fracos ou insuficientes variou de $46 \%$ (E6) a 19\% (E5). Esses resultados indicam que entre $1 / 5$ a $1 / 2$ dos 42 indicadores foram considerados fracos ou insuficientes, indicando que há muitos pontos a serem melhorados na política do município. Além disso, percebe-se que os indicadores de E1, E3 e E5 foram mais bem avaliados, enquanto E2 e E6 apresentaram maior proporção de indicadores fracos e insuficientes e menor proporção de indicadores bons ou muito bons, o que evidencia que as políticas produzem efeitos diferentes nas escolas. Na sequência serão detalhados alguns indicadores dos quesitos, especialmente daqueles considerados fracos ou regulares, que apontaram para aspectos que necessitavam de melhorias na política de inclusão escolar do município. 
No Quesito VI (suporte pedagógico para o aluno PAEE) considerou-se ideal a existência de uma rede de suporte ao aluno PAEE, contando com a existência de AEE, executado na SRM ou em Centro de Atendimento Educacional. Quanto aos demais suportes, considerou-se ainda a existência de profissionais de apoio, apoio pedagógico (reforço escolar), professores de Educação Especial atuando na modalidade itinerante, existência de atendimento em sala de aula (ensino colaborativo ou bidocência) e de atendimento pela equipe multidisciplinar. Pontuou-se também o grau de satisfação dos docentes com todos esses tipos de serviços de apoio listados.

Destaca-se que o serviço o AEE (indicador 11) foi bem avaliado em todas as sete escolas, evidenciando satisfação dos professores regentes, embora este nem sempre ocorresse necessariamente no contraturno. As professoras explicaram que a rede tinha um número considerável de alunos que viviam na zona rural, dependiam de transporte público com horário fixo, o que implicava na oferta do AEE no mesmo turno para que pudessem ser beneficiados pelo serviço, realidade similar encontrada em estudos sobre outros municípios brasileiros (ANACHE et al., 2014).

No que tange ao serviço de apoio pedagógico de professores especializados na sala comum (indicador 13), apenas uma pequena parcela das professoras de ensino reconheceu a existência deste serviço. No grupo focal constatou-se que, a despeito das intenções manifestas em vários documentos oficiais, o município ainda não ofertava apoio do professor especializado na classe comum sistematicamente.

No tocante ao apoio pedagógico de professores itinerantes (indicador 14), embora ele tivesse sido apontado pela gestão, e fossem também mencionado nos documentos oficiais, apenas parte das professoras relataram que este serviço era oferecido em suas respectivas escolas, o que indica que ou o serviço era assistemático, ou não era percebido ou compreendido pelos professores.

Sobre o serviço de apoio pedagógico (indicador 15) ou reforço escolar para alunos com dificuldades acadêmicas, que embora não fossem exclusivos para alunos PAEE, se constituíam em mais uma opção de apoio e permitia reduzir a demanda para o AEE, constatou-se ainda que eram as professoras do AEE que também atendiam os "alunos de apoio". As participantes de todas as escolas, exceto de E5, confirmaram a existência desse serviço e, segundo a gestora, desde que o município vinha adotando critérios mais rígidos no processo de identificação, diminuíra o número de alunos considerados PAEE. Assim, para não fechar serviços ou reduzir carga horária das professoras especializadas, elas assumiram também o serviço de apoio a alunos com dificuldades acadêmicas. 
Quanto ao serviço de profissionais de apoio, contratados para prover suporte às necessidades pessoais dos alunos PAEE (locomoção, alimentação, higiene e comunicação), as professoras informaram que a frequência necessária para este tipo de serviço era baixa, e outras professoras desconheciam a presença destes profissionais na rede de ensino, o que indica que era pequena a presença de alunos com múltiplos e mais severos níveis de impedimentos. Destaca-se que o município também contratava estagiários do curso de Licenciatura em Pedagogia para apoiar alunos em sala de aula.

Por fim, sobre os outros serviços fornecidos por profissionais da equipe multidisciplinar, apenas cerca de $30 \%$ das professoras estavam cientes da existência desse serviço na rede, e nenhuma professora nas escolas E1 e E7 informou que sua escola tivesse esse tipo de apoio. A maioria das professoras que sinalizou ciência deste serviço o avaliou de forma negativa. Assim, embora o município possuísse uma equipe multidisciplinar disponível para a rede há mais de 10 anos, parece que o serviço requeria revisão para atingir maior visibilidade e eficiência.

Em síntese, observou-se que no Quesito VI (suporte pedagógico para o aluno PAEE), o que os impactou não foi a avaliação do AEE em SRM, mas sim os demais serviços (apoio pedagógico, coensino ou bidocência, serviço itinerante, profissional de apoio e equipe multidisciplinar), que foram considerados pelos professores como insuficientes, ou ineficientes. Assim, embora o município provesse organização de uma rede de serviços, de apoio com a oferta diversificada de suporte, para além do AEE em SRM, a estruturação e integração dos serviços, a abrangência para todas as escolas, bem como a visibilidade e eficiência deles, ainda parecia uma meta a ser alcançada.

O segundo quesito avaliado como crítico foi o relacionado ao "Senso de autoeficácia ${ }^{3}$ (Quesito XIII). Este quesito visou avaliar o grau de conhecimento, a autoavaliação do trabalho docente e as demandas formativas. O indicador 39 questionava o grau de conhecimento do docente em relação às necessidades pedagógicas dos seus alunos como um todo, e de seus alunos PAEE em particular. O indicador 40 versava sobre o grau de conhecimento do docente em relação: a) aos procedimentos/materiais/recursos didáticos e equipamentos/recursos tecnológicos que atendessem as necessidades pedagógicas dos seus alunos PAEE; b) as legislações que compunham a política de inclusão escolar; c) aos direitos e deveres do docente enquanto professor de classe comum que possuía alunos PAEE; e d) aos direitos dos

${ }^{3}$ Compreende-se autoeficácia como sendo "[...] um julgamento que o professor faz acerca de suas próprias capacidades para atingir resultados desejados de engajamento e aprendizagem dos alunos, mesmo entre aqueles que podem ser difíceis ou desmotivados" (TSCHANNEN-MORAN; WOOLFOLK-HOY, 2001, p. 783). 
alunos PAEE. $\mathrm{O}$ indicador 41 questionava o docente quanto à autoavaliação sobre suas diferenciações nas práticas pedagógicas para responder às necessidades de seus alunos PAEE e ao manejo de relações de preconceito nas escolas. Por fim, o indicador 42 avaliava as demandas formativas dos docentes, e trazia os mesmos itens do indicador anterior, esperandose, entretanto, que o professor não apontasse demandas formativas sobre os temas.

Neste quesito, o único indicador que apresentou resultados classificados como bons estava relacionado à autoavaliação docente (I41). Os indicadores 41 e 42 são complementares, uma vez que se o docente sinalizasse ter conhecimento, ele também deveria pontuar não precisar de formação sobre este assunto, e os resultados dos professores regentes apresentaram coerência, ou seja, quanto maior o conhecimento menor o índice de necessidade formativa.

O senso de autoeficácia é um dos fatores que determinam as concepções dos professores quanto à capacidade de ensinar seus alunos (CASANOVA; AZZI, 2015), o que sinaliza que os baixos índices obtidos neste quesito como um todo podem compreender problemas relacionados à prática docente, tal como foi expresso pelas professoras de classe comum durante o grupo focal:

[...] eu acho que é frustrante, eu não consigo atender a dificuldade que eles precisam de ajuda. Eu não tenho competência nem habilidade para isso (relato de P17, professora de classe comum).

[...] eu busquei, mas mesmo assim eu não pude ajudar... não tem como" (relato de P3, professora de classe comum).

[...] até a gente entender como é a criança, qual é a dificuldade dela, o caminho que você vai conseguir para chegar até ela... é doloroso. Porque você quer ajudar, você quer fazer, mas ao mesmo tempo você se sente impotente, aí a gente fica procurando ajuda da pessoa que não está sentindo a mesma situação que nós, então assim, eu sinto dificuldade, eu não sou feliz trabalhando com inclusão. Eu acho que não estou preparada para aquela situação, eu sofro demais com isso. (relato da professora P3).

Vale ainda ressaltar que as falas acerca da autoavaliação retratam as diferenças nas culturas profissionais das escolas, uma vez que as professoras avaliaram positivamente o próprio trabalho com os demais alunos, mas nenhuma delas avaliou positivamente seu trabalho com os alunos PAEE (BALL; MAGUIRE; BRAUN, 2016).

Além dos dois quesitos descritos que foram considerados mais críticos, outros quatro quesitos foram avaliados como regulares, e seus indicadores serão analisados para apontar outros pontos que poderiam melhorar a qualidade da política do município, sendo eles: Quesito IV - Identificação do PAEE (4,03), Quesito IX - Estratégias de ensino $(4,54)$, 
Quesito X - Avaliação do ensino e da aprendizagem dos alunos PAEE $(4,90)$ e Quesito VIII Planejamentos $(4,98)$.

O Quesito IV analisava o processo de identificação dos alunos PAEE, composto por um indicador que se considerava ideal que o aluno PAEE possuísse laudo clínico e parecer educacional, que o professor tivesse acesso ao planejamento educacional individualizado ou documento similar do aluno, e que houvesse o máximo possível de integrantes participando do processo de identificação, a fim de minimizar possíveis vieses. Todas as escolas tiveram pontuações entre fraco e regular, resultado este que demonstra que, apesar dos alunos PAEE possuírem identificação, esta ocorria de forma não participativa, pois os alunos ou eram identificados por avaliação médica, ou avaliação do professor, mas, na maioria dos casos, pela instituição especializada filantrópica conveniada com o município. No geral, a identificação era feita por profissionais da saúde, não envolvia profissionais da escola, e embora permitisse certa homogeneidade nos critérios, informações importantes não eram fornecidas para professores que atuariam com os alunos.

O Quesito IX versou sobre a prática pedagógica, e era constituído por cinco indicadores. No indicador 21 esperava-se que os alunos PAEE participassem de todas as atividades da sala comum, havendo diferenciações nas práticas pedagógicas dos docentes quando fosse necessário, e que esta fosse planejada com o apoio do professor de Educação Especial e avaliada como sendo de forma satisfatória, que o professor interagisse em alguns momentos, de forma individualizada com os alunos PAEE e verificar se o mesmo estava fazendo as atividades. Os demais indicadores deste quesito objetivaram verificar se o professor realizava diferenciações, quando estas fossem necessárias para seus alunos PAEE, de conteúdo, das estratégias de ensino, nos materiais/recursos didáticos e na infraestrutura de sala de aula, e, também, se o professor de Educação Especial auxiliava na realização destas medidas

Os dados da Tabela 1 mostram que, com exceção das escolas E2 e E3, as pontuações obtidas no indicador 21 (participação nas atividades) foram consideradas boas, enquanto nos demais indicadores todas as pontuações variaram entre insuficiente e regular. Logo, estes dados permitiram estimar que apesar dos alunos estarem participando das atividades da sala comum, as diferenciações para o ensino não estavam sendo realizadas na medida necessária, o que poderia influenciar diretamente no quanto estes estudantes estariam tendo acesso ao currículo. Os resultados sugerem que os alunos PAEE na classe comum eram submetidos às mesmas condições de ensino dos demais alunos, e se precisassem de alguma medida de equiparação para tornar o ensino mais efetivo, essas medidas não eram adotadas, 
possivelmente porque professores do ensino comum não sabiam como responder à diversidade desses alunos.

O Quesito VIII analisou as formas de planejamentos existentes voltados aos alunos PAEE, sendo composto por dois indicadores. Considerou-se adequado para o indicador 19 a existência de reuniões de planejamento educacional individualizado ou similar para alunos PAEE, bem como, suficiência na carga horária dos docentes de sala comum para planejar o ensino aos alunos PAEE de suas respectivas turmas, e que contasse com uma parceria satisfatória com o professor de educação especial. Para o segundo indicador deste quesito esperava-se que fossem realizadas reuniões documentadas de planejamento curricular coletivo de forma mensal ou bimestral, as quais deveriam ser suficientes para planejar o ensino para os alunos PAEE.

Ao todo, apenas quatro docentes, das escolas E3, E4, E5 e E7, relataram que existiam reuniões juntamente com as professoras de Educação Especial para o planejamento. Parte das demais professoras sinalizaram que apesar de existir este tipo de reunião, elas não participavam. Em contrapartida, quando questionadas quanto ao tempo disponível em suas respectivas cargas horárias destinadas para o planejamento voltado aos alunos PAEE, somente cinco professoras de classe comum apontaram possuir tempo suficiente para tal (uma professora de E2, E4 e E5 e duas de E3).

Os dados acerca do planejamento refletem a importância de uma leitura multidimensional na análise de políticas educacionais, uma vez que esta viabiliza compreender que a atuação da política é reflexo também dos contextos materiais, ou seja, os investimentos sobre os recursos humanos dessas escolas, ou a falta deles. Ball (2016) explicita que quanto mais distante um texto é da realidade escolar, mais complexa será sua atuação, sendo que as desigualdades do contexto local influenciam nesta atuação.

A insuficiência de tempo para o planejamento de atividades para os alunos PAEE explica o baixo índice de diferenciações no ensino pelas professoras regentes:

[...] tem uma que tem laudo e eu tenho 8 que tem uma dificuldade absurda, tem um que eu dou aula de pré para ele, porque nem letra ele conhece. E o resto da classe querendo ler, fazendo as coisas, então eu estou perdidinha, porque eu acho que depois de tanto trabalho, eu quero dar atenção para eles, mas eu não consigo, porque a turma está andando e eles me pedem mais atividade, eles acabam: 'tia já acabei, eu já acabei', e você vai deixar, a classe pegar foto, então eu escolho um por dia, desses 8. Então quer dizer, eu não sinto que eu estou fazendo muita coisa, mas é isso, porque a classe tem que andar. (Relato de professora de classe comum no grupo focal). 
Tais aspectos refletem principalmente os contextos materiais, uma vez que tanto a carga horária docente, parte componente do custo fixo das escolas por meio dos salários dos funcionários, quanto a disponibilização de recursos para atuação com os alunos PAEE em atendimento especializado, são componentes dos orçamentos das escolas, os quais, tal como trazido por Ball, Maguire e Braun (2016, p. 54), “[...] são, talvez, o mais 'material' de todos os fatores contextuais", além de que, em consonância com esta questão, vale ressaltar que as decisões acerca do financiamento podem "[...] moldar as decisões de investimento de maneiras inesperadas, de modo que, em particular, os gastos de capital tornam-se menos sobre prioridades e mais sobre as oportunidades".

No tocante ao ensino dos alunos PAEE, tem-se ainda os dados do Quesito X, sobre a avaliação do ensino e da aprendizagem dos alunos PAEE, composto por seis indicadores. Verificou-se que a maioria das pontuações variou nos indicadores desse quesito entre regular e insuficiente, demonstrando a falta de adequações na avaliação da aprendizagem de alunos PAEE. Também é importante destacar que o indicador 31 teve pontuação nula em todas as escolas, uma vez que todos os professores participantes responderam que não realizavam planos de transição para nenhum aluno do PAEE.

Exceto nos indicadores 30 e 31, que apresentaram certa consistência entre as escolas, sendo o primeiro bem avaliado, e o segundo avaliado negativamente, novamente se percebe certa discrepância nos índices das escolas, o que mais uma vez evidencia como as culturas profissionais variam de acordo com a escola, bem como, que os atores interpretam diferentemente a política do município de inclusão escolar, no tocante a como deve ser a avaliação do desempenho de alunos (BALL; MAGUIRE; BRAUN, 2016).

\section{Considerações finais}

A análise da história do município evidencia momentos de intersecção e momentos de separação entre os caminhos da política do Ministério de Educação e da Secretaria Municipal de Educação. Como momentos de interseção destaca-se a forte marca da instituição especializada no setor, desde o início, o que é condizente com as influências do panorama internacional, que potencializa essa terceirização a fim de economizar na função do Estado de custear a escolarização para o PAEE.

Além disso, constata-se cronometrias acentuadas entre as mudanças nos rumos da política no contexto nacional e local, como por exemplo, a introdução do discurso de inclusão em meados da década de 1990, embora as práticas de integração continuassem em curso no 
município e no país. Em meados dos anos 2000 também se percebe a radicalização do movimento inclusivista em ambos os contextos, e a partir de 2008, quando uma política mais consistente do governo federal amplia o financiamento para viabilizar a perspectiva da educação inclusiva no país, isso produz impacto imediato também no município, que adere à criação das SRM e amplia o número de matrículas de estudantes PAEE em suas escolas.

Em outros aspectos, percebe-se que o município vai assinando sua autoria na construção da política quando, por exemplo, mantém outros serviços de apoio, não previstos na política federal, e configura uma rede de suporte envolvendo professor na classe comum com alunos do PAEE, serviços de equipe multidisciplinar, ensino itinerante, renovando continuamente sua parceria com o terceiro setor de modo a complementar essa rede, além de criar e sustentar um serviço de apoio para alunos com dificuldades, que não são definidos como público-alvo do AEE. Entretanto, isso parece ser feito com restrições de recursos, de modo que o impacto acaba provocando desigualdades no contexto de prática das sete escolas. Em relação à parceria público-privada, ao contrário da confrontação que se observou no contexto nacional entre os formuladores da política de educação inclusiva de 2008 e do movimento das organizações não governamentais do setor, observa-se que no município investigado a relação sempre foi cordial e colaborativa.

No contexto de prática o presente estudo enfocou a rede municipal, composta por sete escolas com matrículas de estudantes do PAEE, buscando analisar a política de inclusão escolar sob a ótica dos professores do ensino comum. As técnicas utilizadas permitiram realizar uma análise abrangente de vários tópicos da política, e evidenciaram como uma mesma política sofre traduções diferentes nos contextos da prática, promove desigualdades, e isso tem impactos diversos na qualidade da escolarização de estudantes do PAEE e na justiça social que se espera que essas políticas corrijam.

Sob a ótica dos professores de classe comum, pontos positivos e negativos puderam ser apontados e permitem, caso haja interesse, aperfeiçoar os efeitos da política de inclusão escolar. Em especial destacam-se aqui quatro aspectos relacionados às várias evidências encontradas e que se referem: à formação de professores, à organização da sistemática de apoio, à função da escola para estudantes PAEE e à desigualdade nos efeitos da política.

A insuficiência de formação na área de Educação Especial, juntamente com a falta de carga horária destinada para um planejamento colaborativo entre as professoras de classe comum e Educação Especial podem estar acarretando dificuldades no tocante às práticas pedagógicas. Isso se percebe também na autoavaliação dos professores quanto ao trabalho exercido, bem como no grau de conhecimento e demandas formativas que apresentam, 
sinalizando problemas na compreensão da política e na atuação com os alunos PAEE. Acredita-se que isso possa ser modificado a partir de formação continuada e de investimentos materiais para melhorar os espaços de compartilhamento entre professores e dos recursos materiais disponibilizados para tal.

Um segundo aspecto de destaque é que tanto a política nacional quanto a política municipal de inclusão escolar ainda concebem a deficiência ou diferença como características pessoais dos alunos, e organiza o apoio circunscrito no espaço especializado, da SRM, enquanto a escola pouco muda para contemplar a diversidade dos alunos. Assim, não parece ser casual a avaliação positiva que professores fazem dos profissionais de apoio que os auxiliam no cotidiano da sala de aula. Nesse sentido, defende-se como essencial a necessidade de mudanças na sistemática de apoio, para que mais suportes sejam centrados no contexto da classe comum e na escola como um todo, e menos circunscrito a atendimentos extraclasse em salas de recursos, que poderiam melhorar a qualidade da política de inclusão escolar.

O terceiro aspecto a se destacar se refere à função principal da escola para alunos PAEE, pois quando se considera os dados dos indicadores sobre as condições de ensino e das avaliações da aprendizagem dos alunos, as avaliações foram menos positivas, enquanto o quesito das interações e relacionamentos são bem avaliados; pode-se deduzir que a preocupação das escolas com alunos PAEE ainda é mais de socializar e menos de dar acesso ao conhecimento baseado no currículo. Assim, é preciso buscar formas de, mais do que acolher, ensinar esses alunos.

Finalmente, o quarto aspecto sublinhado são os efeitos desiguais que uma mesma política no contexto de um município provoca em diferentes escolas, e isso coloca problemas para a gestão no âmbito da política, que deve considerar melhor a diversidade nos contextos situados, nos materiais, nas culturas profissionais e nos contextos externos a fim de melhorar os resultados da política de inclusão escolar no âmbito do município, objetivando reduzir desigualdades e injustiças.

Enfim, com base no estudo o município tem agora um diagnóstico de sua política, subsídios para melhorá-la, e poderá futuramente monitorar e acompanhar suas ações em direção à melhoria da qualidade da política de inclusão escolar.

AGRADECIMENTOS: À FAPESP e ao CNPq pelo financiamento desta pesquisa. 


\section{REFERÊNCIAS}

ANACHE, A. A.; AGOSTINI, M. F.; BRUNO, M. G. M.; SILVA, A. M. Atendimento Educacional Especializado nas Salas de Recursos Multifuncionais do Estado de Mato Grosso do Sul. In: MENDES, E. G.; CIA, F.; D' AFFONSECA, S. M. (Org.). Inclusão escolar e a avaliação do público-alvo da Educação Especial. São Carlos: Marquezine \& Manzini: ABPEE, 2015. v. 2, p. 279-300.

BALL, S. J. Educação Global S.A.: novas redes políticas e o imaginário neoliberal. Trad. Janete Bridon. Ponta Grossa: UEPG, 2014. 270 p.

BALL, S. J.; MAGUIRE, M.; BRAUN, A. Como as escolas fazem as políticas: atuação em escolas secundárias. Ponta Grossa: UEPG, 2016.

BOWE, R.; BALL, S. J.; GOLD, A. Reforming education \& changing schools: case studies in policy sociology. London: Routledge, 1992.

BRASIL. Decreto n. 7.611, de 17 de novembro de 2011. Dispõe sobre a educação especial, o atendimento educacional especializado e dá outras providências. Presidência da República. Diário Oficial da União: Seção 1, Brasília, DF, p. 12, 18 nov. 2011.

BRASIL. Lei n. 13.005, de 25 de junho de 2014. Aprova o Plano Nacional de Educação -PNE e dá outras providências. Presidência da República. Diário Oficial da União: Seção 1, Brasília, DF, p. 1, 26 jun. 2014. PL 8035/2010

BRASIL. Ministério da Educação. $O$ acesso de estudantes com deficiência às escolas e classes comuns da rede regular. Brasília, DF: MEC, 2004.

CASANOVA, D. C. G.; AZZI, R. G. Análise sobre variáveis explicativas da autoeficácia docente. Educar em Revista, Curitiba, n. 58, p. 237-252, out./dez. 2015. DOI:

https://doi.org/10.1590/0104-4060.43236

DOURADO, L. F. Políticas e gestão da educação básica no Brasil: limites e perspectivas. Educação e Sociedade, Campinas, v. 28, n. 100, p. 921-946, out. 2007. DOI: https://doi.org/10.1590/S0101-73302007000300014

IBGE. Estimativa Populacional. 2019. Disponível em: https://www.ibge.gov.br/cidadeseestados/sp. Acesso em: 19 dez. 2019.

INSTITUTO NACIONAL DE PESQUISAS EDUCACIONAIS ANISIO TEIXEIRA. Sinopse Estatística da Educação Básica. Brasília: INEP, 2002.

INSTITUTO NACIONAL DE PESQUISAS EDUCACIONAIS ANISIO TEIXEIRA. Sinopse Estatística da Educação Básica. Brasília: INEP, 2019.

LACERDA, C. B. F.; MENDES, E. G. A avaliação da qualidade da educação especial no âmbito da Educação Básica (Processo Inep: 23112.001311/2016-08). Relatório Final. São Carlos, SP: INEP, 2016. 
LARNER, W.; LAURIE, N. Travelling technocrats, embodied knowledges: globalising privatisation in telecoms and water. Geoforum, v. 41, n. 2, 218-226, mar. 2010.

MAINARDES, J.; MARCONDES, M. I. Entrevista com Stephen J. Ball: um diálogo sobre justiça social, pesquisa e política educacional. Educação \& Sociedade, Campinas, v. 30, n. 106, jan./abr. 2009.

MENDES, E. G. A radicalização do debate sobre a inclusão escolar no Brasil. Revista Brasileira de Educação, Campinas, v. 11, p. 387-405, 2006. DOI:

https://doi.org/10.1590/S1413-24782006000300002

MENDES, E. G.; CIA, F.; TANNÚS-VALADÃO, G. Organização e Funcionamento do Atendimento Educacional Especializado. In: MENDES, E. G.; CIA, F.; TANNÚSVALADÃO, G. (Org.) Inclusão escolar em Foco: organização e funcionamento do atendimento educacional especializado. Marília: ABPEE, 2015. p. 25-36.

SANTOS, V. Análise de indicadores educacionais censitários da política de inclusão escolar: uma proposta metodológica. 2017. 110 f. Dissertação (Mestrado em Educação Especial) -Universidade Federal de São Carlos, São Carlos, 2017.

TSCHANNEN-MORAN, M.; WOOLFOLK-HOY, A. Teacher Efficacy: capturing an elusive construct. Teaching and Teacher Education, v. 17, p. 783-805, 2001.

YIN, R. K. Estudo de caso: planejamento e métodos. 4. ed. Porto Alegre: Bookman, 2010. $248 \mathrm{p}$.

\section{Como referenciar este artigo}

SANTOS, V.; MENDES, E. G. Análise da política de inclusão escolar em um munícipio na perspectiva de professores. Revista Ibero-Americana de Estudos em Educação, v. 16, n. esp. 2, p. 1325-1342, maio 2021. e-ISSN: 1982-5587. DOI: https://doi.org/10.21723/riaee.v16iesp2.15128

Submissão em: $15 / 12 / 2020$

Revisões requeridas em: 28/01/2021

Aprovado em: 03/03/2021

Publicado em: 01/05/2021 